\title{
A New Imperialist Competitive Algorithm for Multiobjective Low Carbon Parallel Machines Scheduling
}

\author{
Zixiao Pan $(\mathbb{D})$, Deming Lei $(\mathbb{D}$, and Qingyong Zhang $(\mathbb{D}$ \\ School of Automation, Wuhan University of Technology, Wuhan 430070, China \\ Correspondence should be addressed to Qingyong Zhang; qyzhang@whut.edu.cn
}

Received 22 October 2017; Revised 6 March 2018; Accepted 11 March 2018; Published 16 April 2018

Academic Editor: Erik Cuevas

Copyright (C) 2018 Zixiao Pan et al. This is an open access article distributed under the Creative Commons Attribution License, which permits unrestricted use, distribution, and reproduction in any medium, provided the original work is properly cited.

\begin{abstract}
This paper considers low carbon parallel machines scheduling problem (PMSP), in which total tardiness is regarded as key objective and total energy consumption is a non-key one. A lexicographical method is used to compare solutions and a novel imperialist competitive algorithm (ICA) is presented, in which a new strategy for initial empires is adopted. Some new improvements are also added in ICA to obtain high quality solutions, which are adaptive assimilation, adaptive revolution, imperialist innovation, and alliance and the novel way of imperialist competition. Extensive experiments are conducted to test the search performance of ICA by comparing it with methods from literature. Computational results show the promising advantages of ICA on low carbon PMSP.
\end{abstract}

\section{Introduction}

Parallel machine scheduling problem (PMSP) is the typical problem in the actual manufacturing processing [1]. Allocating the manufacturing resources and scheduling the production tasks must be designed to achieve the specified performance. In the traditional PMSP, objectives such as total tardiness have extensively been investigated; however, energy consumption and carbon emission are seldom considered $[2,3]$. If there is no consideration on energy related objective, then the corresponding research results are difficult to meet the increasingly stringent requirements of energy conservation and environmental protection on manufacturing activities in China. Thus, it is necessary to focus on low carbon PMSP to improve the traditional scheduling performance and reduce carbon emissions and energy consumption.

In recent years, few papers discussed low carbon PMSP. Several heuristic algorithms has been proposed by Li et al. [4] to minimize makespan or the total completion time under the prerequisite that the total of energy cost and disposal cost is not more than a given threshold. Che et al. [5] gave a mixed integer programming model and two-stage heuristic method on unrelated parallel machine scheduling problem with different power cost. Wang et al. [6] proposed a two-stage algorithm to determine the cutting speed and minimize the maximum completion time of jobs under the given power load peak demand. Liang et al. [3] presented an ant colony optimization (ACO) algorithm to optimize the weighted sum of energy consumption and total tardiness; $\mathrm{Li}$ et al. [2] described the model of the problem and proposed 10 kinds of heuristic algorithms.

Meanwhile, many works have been done on multiobjective PMSP by using various metaheuristics. Lin et al. [7] proposed tabu-enhanced iterated Pareto greedy algorithm to minimize total tardiness, makespan, and total weighted completion time. Ying [8] gave a multiobjective multipoint simulated annealing for PMSP with total tardiness, total weighted completion time, and maximum completion time. $\mathrm{Li}$ et al. [9] provided a hybrid nondominated sorting genetic algorithm-II (NSGA-II [10]) with fuzzy logic controller and an exact method. Pakzad-Moghaddam [11] presented a Lévy flight embedded particle swarm optimization for PMSP with learning and adapting. Afzalirad and Rezaeian [12] reported a multiobjective ant colony optimization to minimize mean weighted flow time and mean weighted tardiness. Zarandi and Kayvanfar [13] applied two multiobjective metaheuristics for PMSP with total cost of tardiness and maximum completion time. 
As mentioned above, low carbon PMSP is seldom studied. The major existing methods for low carbon PMSP are heuristic algorithms. Although metaheuristics have been extensively used to solve multiobjective PMSP without energy related objective, they are hardly applied to optimize low carbon scheduling on parallel machines. To the best of our knowledge, only ACO is found to solve PMSP with energy consumption and other metaheuristics such as imperialist competitive algorithm (ICA) are not used. In addition, the literature on multiobjective PMSP hardly considers the relative importance of objectives. In fact, objectives should be treated differently in many actual manufacturing cases. Take make-to-order production as example, the delay delivery of orders often leads to losses in profits and market reputation; when manufacturers face the high pressure of on-time delivery, it is natural for them to regard on-time delivery as key objective and energy consumption as non-key one, so it is necessary to focus on low carbon PMSP with the consideration on the relative importance of objectives.

ICA is a metaheuristic that mimics sociopolitical imperialist competition for global optimal solution [14]. ICA starts with an initial population, which is a group of countries. The countries with best cost are regarded as imperialists and the rest of countries are called colonies. ICA consists of assimilation of colonies, revolution of colonies, and imperialistic competition among empires and so on. ICA has been successfully applied to solve various optimization problems such as the traveling salesman problem [15], skeletal structure optimization [16], facility layout [17, 18], dynamic economic dispatch scheduling [19], assembly line balancing [20-22], artificial neural network optimization [23], supply chain network design [24], and scheduling [25-34]. However, as stated above, ICA is not used to solve the problem of low carbon parallel machine scheduling. ICA is an effective global optimization method and has strong local search ability with flexible structure [35]. These features make ICA have some advantages in solving low carbon PMSP; for example, it is not necessary to improve local search ability like GA. These things on ICA motivate us to apply ICA to solve low carbon PMSP.

In this study, PMSP with total tardiness (key objective) and total energy consumption (non-key objective) is considered and a novel ICA is proposed for minimizing total tardiness with the consideration on total energy consumption. The lexicographical method is adopted to compare solutions. In ICA, some new strategies are applied to generate high quality solutions, which include the novel method for initial empires, adaptive assimilation, adaptive revolution, imperialist innovation, and alliance and the new imperialist competition. A number of experiments are conducted using many instances. Computational results show the effectiveness and advantages of the new ICA on the low carbon PMSP.

The remainder of the paper is organized as follows. Problem under study and introduction to ICA are described in Sections 2 and 3. ICA for the problem is reported in Section 4. Numerical test experiments on ICA are shown in Section 5 and the conclusions are summarized in the final section and some topics of the future research are provided.

\section{Problem Description}

Low carbon PMSP is described as follows. There are $n$ independent jobs processed on $m$ unrelated parallel machines. Each job $i$ is available at time zero, has a processing time $p_{i j}$ on machine $M_{j}, j=1,2, \ldots, m$, and a due date $d_{i} . E_{j}^{*}$ indicates energy consumption of each machine $M_{j}$ per unit time. At any time, each machine can process at most one job and each job can be processed on at most one machine.

Low carbon PMSP is composed of machine assignment subproblem and scheduling subproblem. The former is to decide an appropriate machine for each job and the latter is to obtain the processing sequence of jobs on each machine.

The goal of the problem is to minimize the following two objectives simultaneously:

$$
\begin{aligned}
& \min f_{1}=\sum_{i=1}^{n} \max \left\{C_{i}-d_{i}, 0\right\} \\
& \min f_{2}=\sum_{j=1}^{m} E_{j}=\sum_{j=1}^{m} \sum_{i=1}^{n} E_{j}^{*} p_{i j} x_{i j},
\end{aligned}
$$

where $f_{1}$ is total tardiness and $f_{2}$ is total energy consumption, $C_{i}$ represents the completion time of job $i, E_{j}$ is the total energy consumption of machine $M_{j}$, and $x_{i j}$ is the $0-1$ variable. If job $i$ is processed on machine $M_{j}, x_{i j}$ is 1 ; otherwise $x_{i j}$ is equal to 0 .

In the literature on multiobjective PMSP, all objectives are often set to have the same importance. In fact, the importance of objectives is not different in many real-life manufacturing situations. For example, in make-to-order production environment, on-time delivery is vital for manufacturers. The delayed delivery will cause loss in revenue, customers, and reputation of company and so on, so it is essential to regard total tardiness as key objective and total energy consumption as non-key one to implement as many on-time deliveries for customers as possible.

The lexicographical method is often utilized to deal with multiple objectives with different importance, which gives key objectives higher priority than non-key ones. When the lexicographical approach is applied, if $f_{1}(x)<f_{1}(y)$ or $f_{1}(x)=f_{1}(y)$ and $f_{2}(x)<f_{2}(y)$, then $x \rightarrow y$, which denotes that $x$ substitutes for $y$. The above conditions mean three cases: (1) $f_{1}(x)<f_{1}(y), f_{2}(x) \leq f_{2}(y)$; (2) $f_{1}(x)<f_{1}(y)$, $f_{2}(x)>f_{2}(y)$; (3) $f_{1}(x)=f_{1}(y), f_{2}(x)<f_{2}(y)$; that is, once $f_{1}(x)>f_{1}(y), y$ cannot be replaced with $x$ even if $f_{2}(x)<f_{2}(y)$. In this study, the lexicographical method is used to compare solutions.

\section{Introduction to ICA}

ICA is a population-based metaheuristic. Each individual of population represents a country and some best countries are selected as imperialists in the initialization. After initial 
empire is built by using an imperialist and colonies, new solutions are generated by the assimilation and revolution of colonies, the exchange of imperialist and colony if possible, and imperialist competition.

The procedure of ICA [14] is shown as follows.

(1) Initialization: generate an initial population $P$.

(2) Construct initial empire: compute the cost $c_{i}$ for each individual; sort $c_{i}$ in descending order for all solutions; select $N_{\text {im }}$ best solutions from $P$ as imperialists; and assign $N_{\text {col }}$ remaining countries to the imperialists.

(3) For each empire, execute assimilation of colonies, perform revolution of some colonies, and exchange position of colony and imperialist if possible.

(4) Achieve imperialist competition.

(5) Eliminate the empire without any countries.

(6) If the termination criterion is not met, go to step (3); otherwise, stop the search.

The cost of a country is calculated according to objective function. The better a solution is, the less its cost is. $N_{\text {im }}$ best solutions with the lowest cost are chosen as imperialists. The rest of countries are set to be colonies. There are $N_{\text {col }}$ colonies; $N_{\text {col }}=N-N_{\text {im }}$. The initial empires are formed by assigning colonies to imperialists according to the power of imperialist

$$
P_{k}=\left|\frac{Y_{k}}{\sum_{v=1}^{N_{\mathrm{im}}} Y_{v}}\right|,
$$

where $P_{k}$ is the power of imperialist $k$ and $Y_{v}=\max _{k}\left\{c_{k}\right\}-$ $c_{v}$ indicates the normalized cost, where $c_{k}$ is the cost of imperialist $k$.

The number of initial colonies possessed by imperialist $k$ is calculated as round $\left\{P_{k} \times N_{\text {col }}\right\}$, where round is a function that gives the nearest integer of a fractional number. $H_{k}$ is the set of colonies of imperialist $k$.

In the assimilation process, a colony in each empire moves $\varepsilon$ along with $e$ direction toward its imperialist. The moving distance $\varepsilon$ is a random number gotten by random distribution in interval $[0, s \times e]$, where $s \in(1,2)$ and $e$ is distance among colony and imperialist. Setting $s>1$ causes the colony to move toward the imperialist direction. However, imperialist cannot absorb their colonies in direct movement, resulting in a deviation from the direct line. The deviation is represented by $\theta$, which follows uniform distribution in $[-\varphi, \varphi]$, where $\varphi$ is an arbitrary parameter.

Revolution is about a change in position of some colonies because of an unexpected changes in their characteristics. For example, by changing the language or religion of a colony, its characteristics will be changed and, accordingly, its position will be changed [14]. The revolution in ICA is similar to mutation in GA, which increases exploration and prevents the early convergence to local optima.

After assimilation and revolution are done in an empire, the cost of each colony is compared with that of its imperialist and a colony is swapped with the imperialist if the colony has less cost than the imperialist.
Imperialist competition is an important step based on the total power of an empire. Let $\mathrm{TC}_{k}$ be the total cost of empire $k$; we first calculate $\mathrm{TC}_{k}$ for each empire $k$ by

$$
\mathrm{TC}_{k}=c_{k}+\zeta \times \text { mean }\{\text { Cost }(\text { colonies of empire } k)\} \text {, }
$$

where $\zeta$ is a positive number between 0 and 1 and close to 0 .

We then compute the normalized total cost of empire $k$ and the power of empire $k$ by

$$
\begin{aligned}
\mathrm{NTC}_{k} & =\max _{h}\left\{\mathrm{TC}_{h}\right\}-\mathrm{TC}_{k}, \\
\mathrm{EP}_{k} & =\left|\frac{\mathrm{NTC}_{k}}{\sum_{v=1}^{N_{\mathrm{im}}} \mathrm{NTC}_{v}}\right| .
\end{aligned}
$$

After a vector $\left[\mathrm{EP}_{1}-s_{1}, \mathrm{EP}_{2}-s_{2}, \ldots, \mathrm{EP}_{N_{\mathrm{im}}}-s_{N_{\mathrm{im}}}\right]$ is defined, the weakest colony from the weakest empire is assigned to the empire with the largest index, where $s_{i}$ denotes a random number following uniform distribution in $[0,1]$.

\section{A Novel ICA for Low Carbon Parallel Machines Scheduling Problem}

In general, imperialist is just updated with the evolved colony and seldom changed in other way; moreover, the search on imperialist and the information exchange between imperialists are seldom considered in the existing ICA. Imperialist is good solution in population and the local and global search on these good solutions are easy to produce high quality solution and improve search efficiency, so it is necessary to introduce the innovation and alliance of imperialist to simulate local search and global search of imperialist. Two objectives of the problem have different importance; some new strategies are applied to form initial empires and do imperialist competition to adapt to the above characteristic. A novel ICA is proposed based on the above ideas. In the following, we describe the detailed steps of ICA.

4.1. Coding and Decoding. For PMSP, each job is required to allocate a machine and processing sequence is needed to decide for all jobs on each machine. In this study, twodimensional coding method is applied to describe a solution of low carbon PMSP. Each solution is represented as two strings.

$$
\begin{aligned}
S=\left\{\begin{array}{l}
S_{1} \\
S_{2}
\end{array}\right\}, & \\
& S_{1}=\left[\pi_{1}, \pi_{2}, \ldots, \pi_{n}\right], S_{2}=\left[B_{1}, B_{2}, \ldots, B_{n}\right],
\end{aligned}
$$

where $S_{1}=\left[\pi_{1}, \pi_{2}, \ldots, \pi_{n}\right]$ is used to decide processing sequence of jobs, $\pi_{i} \in\{1,2, \ldots, n\}$, the second string is for machine assignment, and $B_{i}$ is the machine allocated to job $\pi_{i}$.

Figure 1 shows a solution of low carbon PMSP with 10 jobs and 5 machines. It can be seen that jobs 2, 6, and 7 are processed on machine $M_{5}$ and their processing sequence is 2-7-6. 


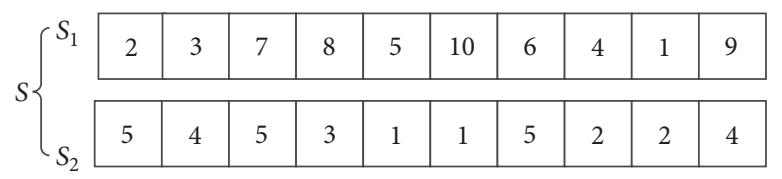

Figure 1: An example of coding strings.

4.2. Initial Empires. After $N$ initial solutions are produced, the cost of all countries is compared and imperialists are chosen, and then each imperialist is assigned colonies. There are two objectives with different importance; we construct initial empires using different ways.

Initial empires are constructed as follows.

(1) For each country $i=1,2, \ldots, N$, compute its main $\operatorname{cost} c_{1 i}=\varepsilon+f_{1}^{i}$ and the secondary $\operatorname{cost} c_{2 i}=f_{2}^{i}$, where $f_{j}^{i}$ indicates the objective $f_{j}$ of solution $i, \varepsilon>0$ is close to zero, and the usage of $\varepsilon$ is to make $\left(\varepsilon+f_{1}^{i}\right)>0$; then calculate $C_{1 i}=1 / c_{1 i}$ and $C_{2 i}=1 / c_{2 i}$.

(2) Sort all countries in the ascending order of the main cost; if more than one country has the same main cost, then sort these countries in the ascending order of the secondary cost. After all countries are sorted, the first $N_{\text {im }}$ countries are chosen as imperialists and other countries are colonies; obviously, $N_{\text {col }}=N-N_{\text {im }}$.

(3) Compute the power using the main cost for each imperialist $k, P_{k}=C_{1 k} / \sum_{l=1}^{N_{\text {im }}} C_{1 l}$ and allocate colonies to each imperialist according to the procedure in Section 3.

Normalized cost is not computed and the reciprocal of cost is used. The reciprocal of cost has the feature that the bigger the reciprocal of cost is, the better the country is; moreover, the usage of the reciprocal of cost can avoid the zero power of at least one imperialist. For those imperialists with the same main cost, they have the identical power, so they should be allocated the same or similar number of colonies.

4.3. Assimilation. In this section, an adaptive assimilation is used and an adaptive assimilation factor $\delta$ is introduced:

$$
\delta=e^{-((g-0.5 G) / G)^{2}},
$$

where $g$ and $G$ denote the current generation and the maximum generation, respectively.

The assimilation is shown below for colony $i \in H_{k}$.

(1) Randomly produce an integer $\alpha \in\{1,2, \ldots, n\}$; define transfer step $\beta=\operatorname{round}\{\delta \times m / 2\}$.

(2) If $(\alpha+\beta) \leq n$, then for the string $S_{1}$ of imperialist $k$, start with the job on position $\alpha$; suppose that the job is located on the position $l$ of string $S_{1}$ of colony $i$; delete job and machine on the position $l$ of two strings of colony $i$; repeat the above steps until the job on position $\alpha+\beta$ is considered; if $(\alpha+\beta)>n$, then start with job on position $\alpha-\beta$; the above steps on imperialist $k$ and colony $i$ are executed until the job on position $\alpha$ is considered.

(3) A new solution $z$ is obtained by inserting the segment of imperialist $k$ between $\alpha$ and $\alpha+\beta$ or $\alpha-\beta$ and $\alpha$ into the position of the first deleted job on colony $i$.

(4) Produce a random number string with length of $n$, $\mathrm{RS}=\left\{s_{1}, s_{2}, \ldots, s_{n}\right\}$.

(5) Start with the first element of RS; if $s_{l}>\delta$, then $B_{l}$ of new solution $z$ is replaced with that of imperialist $k$; repeat the above step until $l=n$.

(6) Lexicographical method is used to compare new solution $z$ and colony $i$ and decide if $z$ can substitute for colony $i$.

Figure 2 gives an example of the above assimilation. Figure 2(a) is about the first assimilation and Figure 2(b) is the second assimilation.

After assimilation is done in an empire, each colony is compared with its imperialist according to the lexicographical method; if a colony is better than its imperialist, then the colony becomes the new imperialist and the former imperialist turns into a colony.

4.4. Revolution. Generally, assimilation makes colony approximate to imperialist and the similarity between colony and its imperialist increases; as a result, the diversity of population decreases and it is harmful to the search efficiency of ICA. To keep high diversity, new strategies are applied to implement revolution of colonies by using an adaptive revolution probability and probability selection matrix.

Probability selection matrix of imperialist $k$ is defined by

$$
Q_{k}=\left[\begin{array}{ccc}
q_{k 11} & \cdots & q_{k 1 n} \\
\vdots & \ddots & \vdots \\
q_{k m 1} & \cdots & q_{k m n}
\end{array}\right],
$$

where $q_{k i j}$ indicates the selection probability of job $i$ processed on machine $j$ in imperialist $k$.

Initially, $q_{k i j}=1 / m$; that is, each machine has the same probability of being chosen to process job $i . q_{k i j}$ is updated by

$$
q_{k i j}^{\text {new }}=\theta \times q_{k i j}+\lambda \times \rho_{k i j}
$$

where $\theta, \lambda \in(0,1)$ are updating factor, $\theta+\lambda=1$; if machine $j$ is allocated to job $i$ in imperialist $k$, then $\rho_{k i j}=1$; otherwise 0 .

After all $q_{k i j}^{\text {new }}$ are obtained, a new probability selection matrix is produced. 


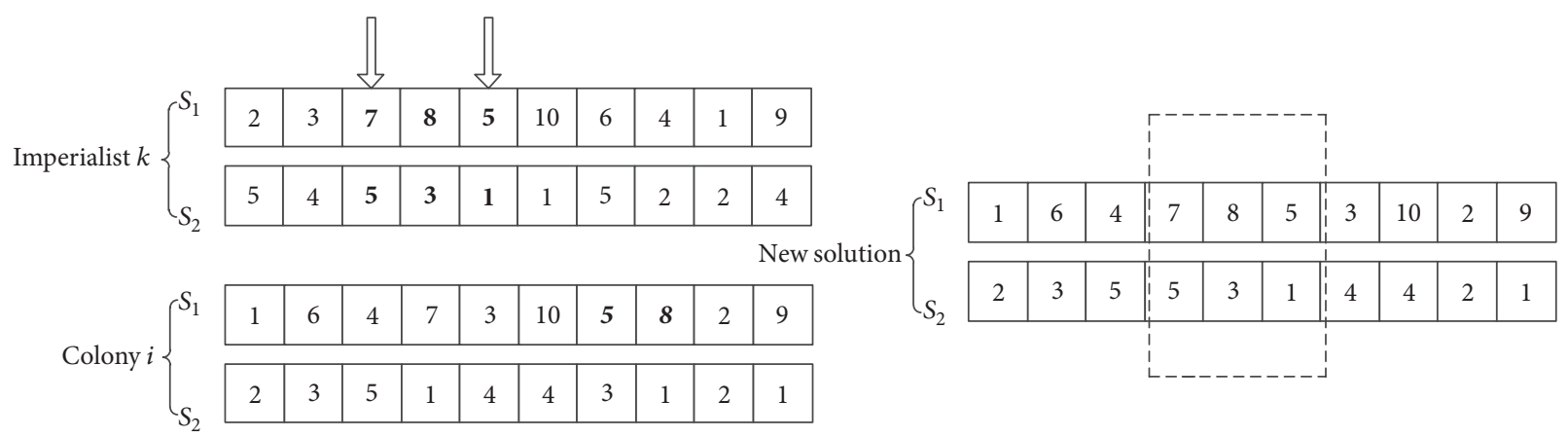

(a)

\begin{tabular}{|c|c|c|c|c|c|c|c|c|c|c|}
\hline Random number & 0.5 & 0.4 & 0.1 & 0.2 & 0.7 & 0.1 & 0.6 & 0.4 & 0.2 & 0.5 \\
\hline Imperialist $k S_{2}$ & 5 & 4 & 5 & 3 & 1 & 1 & 5 & 2 & 2 & 4 \\
\hline & $\sqrt{5}$ & & & & $\sqrt{5}$ & & $\sqrt{5}$ & & & $\sqrt{5}$ \\
\hline$S_{2}$ & 5 & 3 & 1 & 5 & 1 & 1 & 5 & 4 & 2 & 4 \\
\hline & & \# & U & & & & & & & \\
\hline Colony $i S_{2}$ & 2 & 3 & 1 & 5 & 3 & 1 & 4 & 4 & 2 & 1 \\
\hline
\end{tabular}

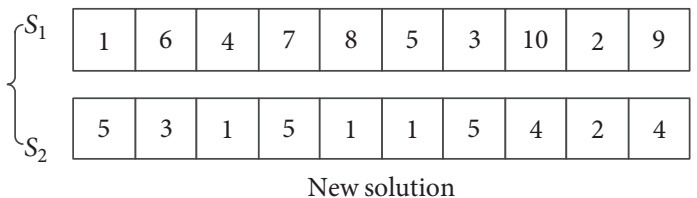

(b)

FIgURE 2: An illustrative example of assimilation.

Revolution probability is fixed in the previous ICA [14$34]$; in this study, an adaptive revolution probability is given by

$$
\operatorname{pr}_{k i}=\min \left\{\left(\frac{\delta\left(C_{1 k}-C_{1 i}\right)}{C_{1 i}}+\operatorname{rand} \times(1-\delta)\right), 1\right\},
$$

where $\mathrm{pr}_{k i}$ is a revolution probability of colony $i$ of imperialist $k$; rand is a random number following uniform distribution on interval $[0,1]$. follows.

The revolution for the colony $i$ of imperialist $k$ is as

(1) Update probability selection matrix of imperialist $k$.

(2) If $\mathrm{pr}_{k i}$ is bigger than a given threshold $\vartheta$, then inverse operator is done on the first string $S_{1}$ of colony $i$; new second string $S_{2}$ is generated by probability selection matrix; the newly generated solution directly substitutes for colony $i$,

where $0<\vartheta<1$.

In step (2), the second string $S_{2}$ is obtained in the following way: for each job $i$, let machine $j$ correspond to interval $\left(\sum_{l=1}^{j-1} q_{k i l}, \sum_{l=1}^{j} q_{k i l}\right]$; start with job $i=1$; if a random number rand $\epsilon\left(\sum_{l=1}^{j-1} q_{k i l}, \sum_{l=1}^{j} q_{k i l}\right]$ is obtained, then machine $j$ is allocated to job $i$; repeat the above step until each job is assigned a machine. Inverse operator is used to reallocate jobs between two random positions in a reverse order.

In the above procedure, no comparison between the new solution and colony before colony is replaced; as a result, the diversity of population improves.
4.5. Imperialist Innovation and Alliance. Imperialist is just updated by assimilation and revolution and the updating rate of imperialist is limited. Imperialist is often good solution in population and the search on good solution is easier to produce high quality solution, so the innovation and alliance of imperialists are introduced to improve the updating rate of imperialist.

Alliance is done between two imperialists and is described below.

(1) Sort all imperialists according to their main cost; let $k=1$.

(2) Repeat the following steps until no pair of imperialist is chosen:

For imperialists $N_{\text {im }}-k, k$, suppose that imperialist $N_{\text {im }}-k$ is better than imperialist $k$; execute the operator between them like the first assimilation; a new solution $z$ is obtained; solution $z$ is compared with imperialist $k$ in terms of the lexicographical method, and imperialist $k$ is replaced with $z$ if the condition is met, $k=k+1$.

Innovation is done for each imperialist and described as follows.

(1) Randomly generate two integers $a<b, a, b \in$ $\{1,2, \ldots, n\}$.

(2) In two strings of imperialist $k$, reverse jobs and machines between $a$ and $b$.

(3) Start with $B_{i}(i=1)$ of $S_{2}$ of imperialist $k$; produce a random integer number rand $\epsilon[1,10]$ and if rand $>\mu$, 


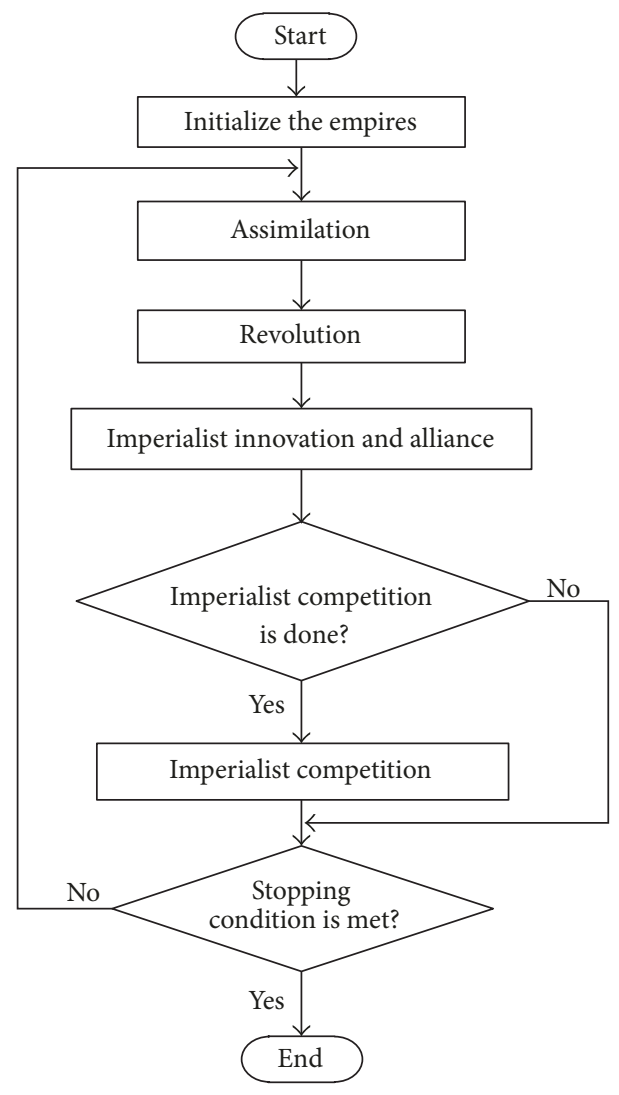

FIgURE 3: The flowchart of new ICA.

then assign a new machine for $B_{i}$. A new solution $z$ is obtained.

(4) The lexicographical method is used to decide if imperialist $k$ can be replaced with $z$,

where $\mu$ is an integer.

We decide $\mu=5$ based on a number of experiments. When rand is chosen from $[1,10]$, the condition rand $>\mu$ means that $B_{i}$ is changed with the possibility of $50 \%$.

4.6. Imperialist Competition. Imperialist competition is the reallocating process of colonies. However, if imperialist competition is done in high frequency, $N_{\mathrm{im}}$ empires can be easily combined into one empire and prematurity may occur, so, in this study, imperialist competition is not done in each generation and is executed every $g_{i c}$ generations. In this study, $g_{i c}=50$ based on a number of experiments.

There are main cost and second cost for a country, so we calculate $\mathrm{TC}_{1 k}$ and $\mathrm{TC}_{2 k}$, which is defined by

$$
\begin{gathered}
\mathrm{TC}_{1 k}=(1-\eta) C_{1 k}+\frac{\eta \sum_{i \in H_{k}} C_{1 i}}{\left|H_{k}\right|}, \\
\mathrm{TC}_{2 k}=(1-\eta) C_{2 k}+\frac{\eta \sum_{i \in H_{k}} C_{2 i}}{\left|H_{k}\right|},
\end{gathered}
$$

where $\mathrm{TC}_{l k}$ is the weighted sum of $C_{l k}$ of imperialist $k$ and the average $C_{l i}$ of all colonies of imperialist $k, l=1,2$. $\eta$ is a real number; we set $\eta=0.1$ by a number of test experiments.
When the condition of imperialist competition is met, imperialist competition is executed as follows.

(1) Calculate $\mathrm{TC}_{1 k}, \mathrm{TC}_{2 k}$ and $\mathrm{NTC}_{1 k}, \mathrm{NTC}_{2 k}$ of each empire $k=1,2, \ldots, N_{\text {im }}$.

(2) Compute power $\mathrm{TP}_{1 k}=\mathrm{NTC}_{1 k} / \sum_{l=1}^{N_{\mathrm{im}}} \mathrm{NTC}_{1 l}$ and $\mathrm{TP}_{2 k}=\mathrm{NTC}_{2 k} / \sum_{l=1}^{N_{\text {im }}} \mathrm{NTC}_{2 l}$.

(3) Produce a vector $R=\left[r_{1}, r_{2}, \ldots, r_{N_{\text {im }}}\right]$, where $r_{i}, i=$ $1,2, \ldots, n$ follows uniform distribution on $[0,1]$.

(4) Define vectors $D_{1}=\left[\mathrm{TP}_{11}-r_{1}, \mathrm{TP}_{12}-r_{2}, \ldots, \mathrm{TP}_{1 N_{\mathrm{im}}}-\right.$ $\left.r_{\mathrm{im}}\right]$ and $D_{2}=\left[\mathrm{TP}_{21}-r_{1}, \mathrm{TP}_{22}-r_{2}, \ldots, \mathrm{TP}_{2 N_{\mathrm{im}}}-r_{\mathrm{im}}\right]$.

(5) Decide the maximum element in vector $D_{1}$; if only one element, for instance, the $k$ th element in $D_{1}$, reaches the maximum value, then allocate the weakest colony from the weakest empire into empire $k$; if more than one element is equal to the maximum value, for example, the $k_{1}$ th element and $k_{2}$ th element, then compare the corresponding elements in $D_{2}$; if the $k_{1}$ th element is bigger than $k_{2}$ th element, then allocate the weakest colony from the weakest empire into empire $k_{1}$,

where $\mathrm{NTC}_{1 k}=\mathrm{TC}_{1 k}-\min _{l}\left\{\mathrm{TC}_{1 l}\right\}, \mathrm{NTC}_{2 k}=\mathrm{TC}_{2 k}-$ $\min _{l}\left\{\mathrm{TC}_{2 l}\right\}$.

4.7. Algorithm Description. Figure 3 describes the flowchart of our ICA. The termination condition is the maximum 
number of objective function evaluations. Compared with the basic ICA, our ICA has the following new features. (1) Imperialist innovation and alliance are introduced to make full use of the advantages of imperialists as good solutions. (2) Adaptive mechanism is used in assimilation and revolution. (3) Revolution is implemented in a new way; there is no comparison between the obtained new solution and colony and the new solution directly substitutes for colony.

\section{Computational Experiments}

To test the performance of ICA for the low carbon PMSP, extensive experiments are conducted on a set of problems. All experiments are implemented by using Matlab2015b and run on $4.0 \mathrm{G}$ RAM $2.20 \mathrm{GHz}$ CPU PC.

5.1. Test Instances and Comparative Algorithms. 31 instances are randomly produced, in which $p_{i j}$ is from interval $[1,100]$, energy consumption of machine per unit time $E_{j}^{*}$ is selected from $[1,50]$, and due date $d_{i}$ is set to $\rho \max _{j=1,2, \ldots, m} p_{i j}, \rho=0.3$.

As stated above, only ACO [3] is applied to solve low carbon PMSP, so we first choose ACO [3] as comparative algorithm. In ACO [3], total tardiness and energy consumption are combined into one objective by the weighted method. We revised ACO as follows: lexicographical method is used to compare solutions and pheromone is updated according to key objective. Jin et al. [36] reported a multiobjective memetic algorithm (MOMA) for integrated process planning and scheduling. MOMA can be directly used to solve the considered PMSP, so we apply MOMA as another comparative algorithm. Meanwhile, in order to prove the effectiveness of the new ICA, we construct ICA1 as a comparative algorithm without adaptive assimilation factor, the adaptive revolution probability, or imperialist innovation and alliance. On the other hand, some metaheuristics such as the famous NSGAII cannot be directly used to solve our problem because no relative importance of objectives is adopted in these algorithms.

5.2. Results and Discussions. New ICA has four parameters: $N$ (population size), $N_{\text {im }}$ (number of imperialist), $\vartheta$ (threshold of revolution rate), and $G$ (maximum generation). We obtained the following settings for parameters: $N=100$, $N_{\text {im }}=10$, and $\vartheta=0.98$ and results on $G$ are shown in Table 1 .

We directly adopt all settings of parameters of ACO proposed by Liang et al. [3] except stopping condition. The parameter settings of MOMA are chosen from Jin et al. [36] except that the termination criterion and the parameter settings of ICA1 are the same as the new ICA. Four algorithms have the same stopping condition: when the maximum generation is reached, the search is stopped. Each algorithm randomly runs 20 times for each instance. The computational results are shown in Tables 2, 3, and 4. In each run an algorithm outputs a final solution: BEST indicates the best final solution founded, WOR denotes the worst final solution in 20 runs, and AVG is the average value of 20 final solutions. Table 5 reports the average running time of four algorithms. Figure 4 shows the comparison of four algorithms for convergence.
TABLE 1: Maximum generation of all instances.

\begin{tabular}{|c|c|}
\hline$m \times n$ & $G$ \\
\hline $10 \times 5$ & 1000 \\
\hline $20 \times 5$ & 1000 \\
\hline $20 \times 8$ & 1000 \\
\hline $30 \times 5$ & 2000 \\
\hline $30 \times 8$ & 2000 \\
\hline $30 \times 10$ & 2000 \\
\hline $50 \times 5$ & 3000 \\
\hline $50 \times 8$ & 3000 \\
\hline $50 \times 10$ & 3000 \\
\hline $50 \times 12$ & 3000 \\
\hline $80 \times 8$ & 4000 \\
\hline $80 \times 10$ & 4000 \\
\hline $80 \times 12$ & 4000 \\
\hline $80 \times 15$ & 4000 \\
\hline $100 \times 10$ & 5000 \\
\hline $100 \times 12$ & 5000 \\
\hline $100 \times 15$ & 5000 \\
\hline $120 \times 10$ & 6000 \\
\hline $120 \times 12$ & 6000 \\
\hline $120 \times 15$ & 6000 \\
\hline $150 \times 10$ & 7000 \\
\hline $150 \times 15$ & 7000 \\
\hline $150 \times 20$ & 7000 \\
\hline $180 \times 10$ & 8000 \\
\hline $180 \times 15$ & 8000 \\
\hline $180 \times 20$ & 8000 \\
\hline $200 \times 10$ & 9000 \\
\hline $200 \times 15$ & 9000 \\
\hline $200 \times 20$ & 9000 \\
\hline $220 \times 15$ & 10000 \\
\hline $220 \times 20$ & 10000 \\
\hline
\end{tabular}

As shown in Table 2, when the best solutions of four algorithms are compared with the lexicographical method, it can be found that BEST of ICA is better than that of MOMA, ACO, and ICA1 on 30 of 31 instances; moreover, with respect to best solution, two objectives of ICA are less than or equal to those of other three algorithms on 21 instances. Obviously, new ICA converges better than MOMA, ACO, and ICA1. It also can be seen that WOR of ICA is also better than that of other algorithms on 29 instances. The worst final solution of ICA has smaller objectives than or identical objective value with that of MOMA, ACO, and ICA1 on 18 instances, so we can conclude that new ICA performs better than its comparative algorithms in stability. The results in Table 4 also reveal that new ICA is also superior to other three algorithms in average performance; in a word, new ICA can provide better results than MOMA, ACO, and ICA1 using less computational times.

It can be found from Tables 2 and 3 that when new ICA obtains smaller total tardiness than MOMA, ACO, and ICA1, total energy consumption generated by ICA is often 


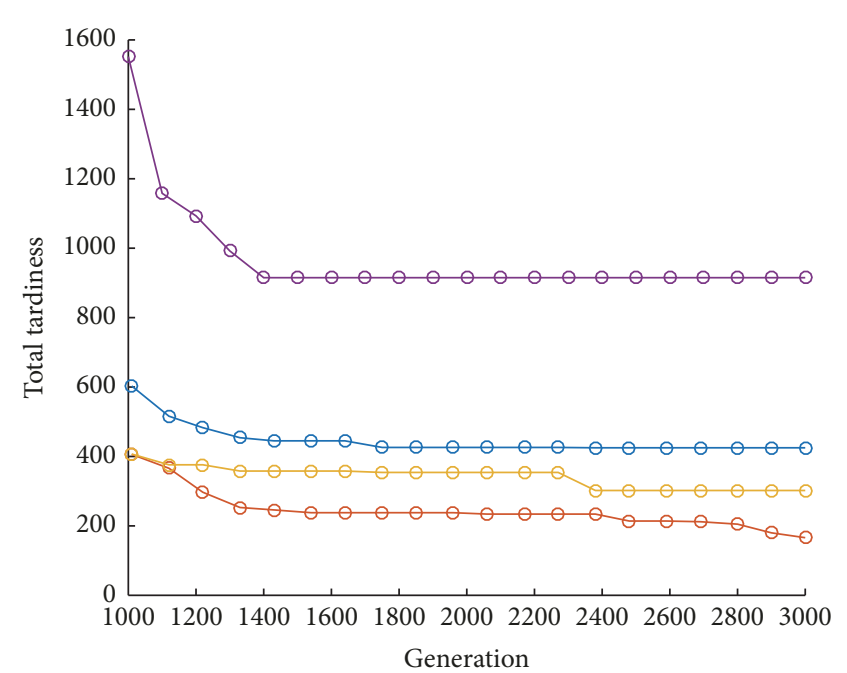

$\multimap$ MOMA $\odot$ ACO

(a) The comparison for total tardiness in $50 \times 10$

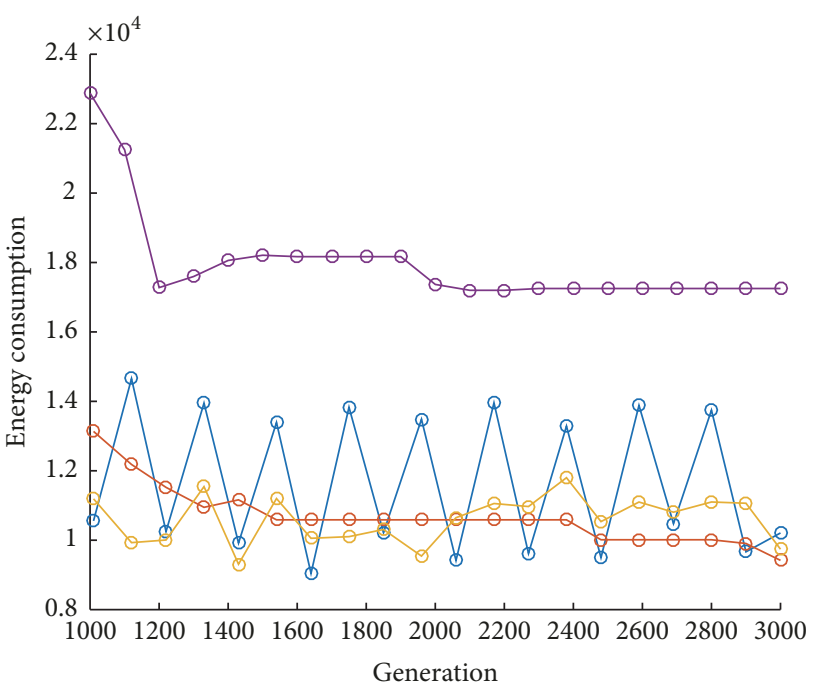

$\multimap$ MOMA - ACO

(b) The comparison for energy consumption in $50 \times 10$

FIgURE 4: The comparison of four algorithms for convergence.

TABLE 2: Comparisons among MOMA, ACO, ICA1, and new ICA on BEST.

\begin{tabular}{|c|c|c|c|c|c|c|c|c|}
\hline \multirow{2}{*}{$m \times n$} & \multicolumn{2}{|c|}{ MOMA } & \multicolumn{2}{|c|}{$\mathrm{ACO}$} & \multicolumn{2}{|c|}{ ICA1 } & \multicolumn{2}{|c|}{ New ICA } \\
\hline & $f_{1}$ & $f_{2}$ & $f_{1}$ & $f_{2}$ & $f_{1}$ & $f_{2}$ & $f_{1}$ & $f_{2}$ \\
\hline $10 \times 5$ & 65 & 4284.8 & 56 & 4316.5 & 56 & 4316.5 & 56 & 4316.5 \\
\hline $20 \times 5$ & 459 & 6357.5 & 299 & 4979.1 & 285 & 5095.2 & 283 & 4979.1 \\
\hline $20 \times 8$ & 64 & 9017.8 & 34 & 8732.8 & 94 & 10595.9 & 32 & 8790.1 \\
\hline $30 \times 5$ & 1003 & 13959.3 & 817 & 13228.5 & 701 & 12838.2 & 690 & 14352.3 \\
\hline $30 \times 8$ & 240 & 9133.2 & 199 & 9363.0 & 252 & 11925.5 & 155 & 9363.0 \\
\hline $30 \times 10$ & 173 & 6969.1 & 131 & 7356.4 & 234 & 8543.3 & 97 & 7063.8 \\
\hline $50 \times 5$ & 3673 & 14550.2 & 3043 & 17291.1 & 2848 & 19014.1 & 2104 & 16113.8 \\
\hline $50 \times 8$ & 826 & 15724.8 & 617 & 14706.7 & 1430 & 21788.4 & 355 & 14119.3 \\
\hline $50 \times 10$ & 355 & 10224.1 & 276 & 9760.1 & 779 & 17857.8 & 156 & 9836.1 \\
\hline $50 \times 12$ & 197 & 15869.4 & 190 & 15325.0 & 582 & 23658.3 & 61 & 14486.2 \\
\hline $80 \times 8$ & 3160 & 20287.4 & 3257 & 20065.4 & 4413 & 32267.7 & 1907 & 19370.0 \\
\hline $80 \times 10$ & 1197 & 16631.4 & 1303 & 10504.0 & 2937 & 25036.6 & 621 & 10718.7 \\
\hline $80 \times 12$ & 864 & 22537.9 & 896 & 22677.1 & 2187 & 39664.3 & 375 & 20038.8 \\
\hline $80 \times 15$ & 1073 & 19746.7 & 343 & 18324.4 & 1919 & 51067.8 & 115 & 17289.6 \\
\hline $100 \times 10$ & 2622 & 21530.8 & 3372 & 24818.4 & 4756 & 34906.4 & 1918 & 21792.5 \\
\hline $100 \times 12$ & 1917 & 29604.6 & 1697 & 26113.0 & 4290 & 56967.8 & 826 & 24302.9 \\
\hline $100 \times 15$ & 658 & 18938.2 & 911 & 20650.6 & 4131 & 52051.7 & 345 & 18906.4 \\
\hline $120 \times 10$ & 4405 & 40114.0 & 4450 & 35485.3 & 9308 & 76955.5 & 2344 & 32028.0 \\
\hline $120 \times 12$ & 2595 & 27478.8 & 3033 & 28249.0 & 5842 & 56348.2 & 1325 & 26127.6 \\
\hline $120 \times 15$ & 1028 & 22847.1 & 1104 & 21434.9 & 6272 & 76945.4 & 391 & 19089.7 \\
\hline $150 \times 10$ & 8522 & 51214.5 & 9486 & 54150.3 & 18380 & 102872.3 & 4785 & 44933.8 \\
\hline $150 \times 15$ & 2554 & 32634.0 & 2775 & 33334.5 & 10905 & 99357.3 & 1270 & 28796.0 \\
\hline $150 \times 20$ & 435 & 21052.4 & 723 & 21349.2 & 7844 & 97740.7 & 186 & 20600.5 \\
\hline $180 \times 10$ & 8773 & 45778.1 & 11599 & 48224.9 & 28093 & 124923.7 & 5854 & 42417.5 \\
\hline $180 \times 15$ & 3450 & 34563.6 & 4590 & 34576.2 & 18005 & 115186.6 & 2120 & 30726.2 \\
\hline $180 \times 20$ & 1159 & 25442.1 & 1613 & 24713.5 & 11510 & 110158.3 & 515 & 24968.7 \\
\hline $200 \times 10$ & 12403 & 67204.2 & 17142 & 65871.5 & 36559 & 169238.0 & 8303 & 57896.8 \\
\hline $200 \times 15$ & 4921 & 31526.7 & 6674 & 32713.7 & 22069 & 102733.5 & 2984 & 29347.2 \\
\hline $200 \times 20$ & 2378 & 35482.6 & 2934 & 33490.5 & 14639 & 125260.9 & 1106 & 30533.7 \\
\hline $220 \times 15$ & 5451 & 57772.2 & 7312 & 52861.4 & 30813 & 187739.9 & 3079 & 45814.6 \\
\hline $220 \times 20$ & 2399 & 28342.2 & 3017 & 28682.6 & 20876 & 122877.3 & 1036 & 25557.8 \\
\hline
\end{tabular}


TABLE 3: Comparisons among MOMA, ACO, ICA1, and new ICA on WOR.

\begin{tabular}{|c|c|c|c|c|c|c|c|c|}
\hline \multirow{2}{*}{$m \times n$} & \multicolumn{2}{|c|}{ MOMA } & \multicolumn{2}{|c|}{$\mathrm{ACO}$} & \multicolumn{2}{|c|}{ ICA1 } & \multicolumn{2}{|c|}{ New ICA } \\
\hline & $f_{1}$ & $f_{2}$ & $f_{1}$ & $f_{2}$ & $f_{1}$ & $f_{2}$ & $f_{1}$ & $f_{2}$ \\
\hline $10 \times 5$ & 65 & 4284.8 & 58 & 3978.7 & 104 & 5567.2 & 59 & 3562.7 \\
\hline $20 \times 5$ & 509 & 6621.4 & 345 & 5026.6 & 580 & 5470.6 & 301 & 5090.9 \\
\hline $20 \times 8$ & 87 & 8790.1 & 50 & 9282.9 & 307 & 13706.5 & 59 & 8882.9 \\
\hline $30 \times 5$ & 1149 & 15091.0 & 906 & 13940.9 & 1063 & 17773.4 & 704 & 12740.3 \\
\hline $30 \times 8$ & 283 & 9367.8 & 261 & 9097.7 & 572 & 15152.1 & 195 & 9154.0 \\
\hline $30 \times 10$ & 146 & 7059.2 & 156 & 7640.0 & 712 & 13399.8 & 128 & 8048.4 \\
\hline $50 \times 5$ & 3864 & 14856.1 & 3365 & 18781.4 & 4790 & 26693.8 & 2164 & 16395.0 \\
\hline $50 \times 8$ & 911 & 17356.0 & 725 & 13732.6 & 2754 & 33195.8 & 400 & 13861.2 \\
\hline $50 \times 10$ & 403 & 10306.2 & 356 & 9656.7 & 2019 & 27188.6 & 193 & 9783.6 \\
\hline $50 \times 12$ & 359 & 17569.1 & 229 & 15118.9 & 1659 & 36914.3 & 116 & 16647.7 \\
\hline $80 \times 8$ & 3403 & 20247.4 & 3492 & 19547.1 & 7946 & 38695.1 & 2064 & 19526.6 \\
\hline $80 \times 10$ & 1310 & 14868.1 & 1389 & 12914.2 & 6092 & 33508.8 & 768 & 12133.7 \\
\hline $80 \times 12$ & 1062 & 24214.1 & 990 & 23511.2 & 4480 & 53144.3 & 474 & 23154.6 \\
\hline $80 \times 15$ & 1293 & 31052.0 & 395 & 19309.4 & 3968 & 68440.8 & 197 & 19277.9 \\
\hline $100 \times 10$ & 2830 & 23633.6 & 3511 & 23270.9 & 9211 & 58114.9 & 2063 & 21944.6 \\
\hline $100 \times 12$ & 2348 & 35228.8 & 1857 & 25752.1 & 8102 & 77000.0 & 938 & 24496.9 \\
\hline $100 \times 15$ & 827 & 20484.6 & 944 & 18988.6 & 6582 & 68940.3 & 453 & 20752.6 \\
\hline $120 \times 10$ & 4754 & 44360.3 & 4807 & 37446.8 & 15357 & 107062.8 & 2531 & 33887.4 \\
\hline $120 \times 12$ & 3956 & 31656.2 & 3372 & 29914.8 & 13505 & 80182.4 & 1505 & 27595.6 \\
\hline $120 \times 15$ & 1617 & 29421.0 & 1207 & 22810.1 & 10015 & 99105.3 & 535 & 22093.5 \\
\hline $150 \times 10$ & 9185 & 55098.9 & 10230 & 53571.8 & 30227 & 132490.7 & 5212 & 48209.9 \\
\hline $150 \times 15$ & 2822 & 33247.7 & 3066 & 34228.2 & 20336 & 138752.4 & 1455 & 33806.7 \\
\hline $150 \times 20$ & 714 & 22619.7 & 811 & 21343.0 & 13539 & 129451.0 & 285 & 22320.0 \\
\hline $180 \times 10$ & 9683 & 56680.2 & 12490 & 48304.2 & 46450 & 179610.1 & 6226 & 43798.2 \\
\hline $180 \times 15$ & 4468 & 41928.6 & 5017 & 37636.6 & 25597 & 148557.0 & 2497 & 34139.7 \\
\hline $180 \times 20$ & 1569 & 30121.8 & 1842 & 26161.1 & 19943 & 153944.5 & 685 & 26339.8 \\
\hline $200 \times 10$ & 13439 & 79430.0 & 17822 & 67572.5 & 54463 & 199616.5 & 8687 & 58893.9 \\
\hline $200 \times 15$ & 6084 & 35743.2 & 7162 & 34106.5 & 34111 & 113485.7 & 3262 & 30318.8 \\
\hline $200 \times 20$ & 3125 & 43934.0 & 3118 & 34478.9 & 25433 & 168075.6 & 1301 & 32160.0 \\
\hline $220 \times 15$ & 6490 & 62264.3 & 7729 & 52519.3 & 46779 & 238774.3 & 3299 & 47618.0 \\
\hline $220 \times 20$ & 2829 & 31359.5 & 3382 & 29615.7 & 32229 & 165592.3 & 1248 & 28203.8 \\
\hline
\end{tabular}

less than the corresponding results of MOMA, ACO, and ICA1. This feature shows that total energy consumption really diminishes with the optimization of total tardiness. The lexicographical method is effective.

A nonparametric significance test known as Wilcoxon signed-rank test is conducted $[37,38]$. In this test, a null hypothesis is assumed: there is no difference between the median of the solutions achieved by two compared algorithms. The significance level is $\alpha=0.05$. $p$ value is produced by Wilcoxon signed-rank test for the pairwise comparison of two groups. If $p$ value is smaller than or equal to significance level $\alpha$, the null hypothesis is rejected. Experimental results of
Wilcoxon signed-rank test for new ICA and other algorithms are shown in Tables 6, 7, and 8 .

As shown in Tables 6, 7, and 8, $p$ value of Wilcoxon signed-rank test is 0.001 . The results show that new ICA performs significantly better than MOMA, ACO, and ICA1 in statistical meaning.

The good performance of new ICA mainly results from its inclusion of imperialist innovation and alliance and the adaptive implementation of assimilation and revolution. These strategies intensify global search ability and improve local search ability; moreover, the search of imperialist is reinforced; as a result, the good balance between exploration 
TABLE 4: Comparisons among MOMA, ACO, ICA1, and new ICA on AVG.

\begin{tabular}{|c|c|c|c|c|c|c|c|c|}
\hline \multirow{2}{*}{$m \times n$} & \multicolumn{2}{|c|}{ MOMA } & \multicolumn{2}{|c|}{$\mathrm{ACO}$} & \multicolumn{2}{|c|}{ ICA1 } & \multicolumn{2}{|c|}{ New ICA } \\
\hline & $f_{1}$ & $f_{2}$ & $f_{1}$ & $f_{2}$ & $f_{1}$ & $f_{2}$ & $f_{1}$ & $f_{2}$ \\
\hline $10 \times 5$ & 65.0 & 4284.8 & 56.4 & 4299.6 & 68.1 & 4144.9 & 57.0 & 4090.4 \\
\hline $20 \times 5$ & 486.0 & 5676.6 & 331.5 & 5006.6 & 390.8 & 5288.5 & 292.1 & 4976.3 \\
\hline $20 \times 8$ & 71.2 & 8852.8 & 40.9 & 8772.5 & 166.3 & 113187 & 42.8 & 8815.5 \\
\hline $30 \times 5$ & 1038.5 & 14091.6 & 864.7 & 13590.1 & 865.2 & 14598.2 & 693.1 & 13229.3 \\
\hline $30 \times 8$ & 261.3 & 9382.7 & 234.4 & 9702.1 & 373.3 & 12442.4 & 169.2 & 9817.7 \\
\hline $30 \times 10$ & 160.5 & 7492.1 & 144.2 & 7429.6 & 466.1 & 12116.8 & 113.2 & 7580.5 \\
\hline $50 \times 5$ & 3783.3 & 16170.0 & 3212.2 & 16624.5 & 3745.1 & 21015.5 & 2122.5 & 15361.4 \\
\hline $50 \times 8$ & 867.0 & 16640.3 & 681.7 & 14456.6 & 1964.6 & 27652.4 & 379.2 & 14215.9 \\
\hline $50 \times 10$ & 378.0 & 10193.2 & 327.0 & 9917.7 & 1237.8 & 22180.8 & 174.3 & 9939.3 \\
\hline $50 \times 12$ & 225.6 & 15917.4 & 210.9 & 15568.1 & 1000.85 & 28624.0 & 91.3 & 15580.1 \\
\hline $80 \times 8$ & 3281.2 & 20688.2 & 3353.5 & 20922.4 & 5821.7 & 34995.0 & 1960 & 19405.7 \\
\hline $80 \times 10$ & 1262.8 & 13977.3 & 1341.8 & 12847.2 & 4251.4 & 31254.6 & 655.5 & 11552.4 \\
\hline $80 \times 12$ & 951.7 & 22710.6 & 941.7 & 22686.0 & 3291.4 & 48613.3 & 416.1 & 20696.4 \\
\hline $80 \times 15$ & 1160.0 & 30869.8 & 380.9 & 18989.3 & 2987.9 & 62847.9 & 163.6 & 18456.3 \\
\hline $100 \times 10$ & 2675.1 & 23006.5 & 3442.7 & 23513.0 & 7412.3 & 50818.8 & 1972.7 & 22049.0 \\
\hline $100 \times 12$ & 2005.0 & 29498.0 & 1799.4 & 26628.0 & 6143.1 & 67251.9 & 869.1 & 24351.5 \\
\hline $100 \times 15$ & 750.9 & 19579.8 & 950.5 & 19980.4 & 5321.6 & 60929.4 & 405.7 & 19255.9 \\
\hline $120 \times 10$ & 4479.1 & 39922.6 & 4707.4 & 35942.0 & 12306.8 & 91298.3 & 2416.6 & 32750.1 \\
\hline $120 \times 12$ & 2890.0 & 29353.2 & 3270.4 & 29007.4 & 9670.1 & 71468.9 & 1406.2 & 26648.1 \\
\hline $120 \times 15$ & 1340.0 & 25829.9 & 1142.6 & 21910.3 & 7699.5 & 85988.5 & 434.7 & 19997.7 \\
\hline $150 \times 10$ & 8872.0 & 52160.2 & 9851.8 & 51504.6 & 24125.9 & 118001.4 & 4895.2 & 45484.0 \\
\hline $150 \times 15$ & 2688.6 & 34085.4 & 2956.4 & 32941.1 & 14207.1 & 115536.4 & 1339.4 & 30486.1 \\
\hline $150 \times 20$ & 576.6 & 22785.5 & 770.1 & 21811.6 & 10505.2 & 114924.6 & 231.8 & 20557.3 \\
\hline $180 \times 10$ & 9223.9 & 51447.5 & 12186.2 & 48382.6 & 33668.1 & 135846.2 & 6006.9 & 43092.3 \\
\hline $180 \times 15$ & 3855.4 & 38299.9 & 4844.6 & 36326.4 & 21764.8 & 127503.5 & 2274.0 & 32632.4 \\
\hline $180 \times 20$ & 1323.8 & 28139.1 & 1757.2 & 26291.4 & 15884.7 & 132815.9 & 579.9 & 24413.5 \\
\hline $200 \times 10$ & 12727.7 & 70269.8 & 17488 & 67196.6 & 42108.6 & 171637.6 & 8687.0 & 59111.7 \\
\hline $200 \times 15$ & 5581.1 & 35524.7 & 7020.9 & 33513.2 & 28278.5 & 115073.2 & 3086.6 & 29394.6 \\
\hline $200 \times 20$ & 2759.7 & 37720.7 & 3019.1 & 34398.4 & 20894.1 & 150294.9 & 1199.6 & 31177.5 \\
\hline $220 \times 15$ & 5962.6 & 58193.9 & 7539.0 & 53527.8 & 37930.3 & 215962.5 & 3213.7 & 47173.8 \\
\hline $220 \times 20$ & 2562.9 & 28535.4 & 3244.6 & 29012.2 & 26132.5 & 144387.1 & 1125.2 & 25759.7 \\
\hline
\end{tabular}

and exploitation is kept; thus, we can conclude that new ICA is a very competitive method for low carbon PMSP.

\section{Conclusions}

PMSP has been extensively considered in the past decade; however, these results are mainly about the optimization of time related indices such as total tardiness. Energy related objective is seldom coped with in parallel machines environments. In this study, low carbon PMSP is studied, in which total tardiness is regarded as key objective and total energy consumption is non-key one. A lexicographical method is used to compare solutions and a novel ICA is presented by using new strategy for forming initial empires, an adaptive assimilation factor and an adaptive revolution, imperialist innovation, and alliance and the way to imperialist competition. Extensive experiments are conducted and ICA is compared with ACO and MOMA. The results validate that new ICA has promising advantages on low carbon PMSP.

We will continue to focus on low carbon PMSP in the near future; for example, we pay attention to PMSP with energy consumption constraint and find a good way to deal with the energy constraint. The applications of ICA to other production scheduling problems such as distributed scheduling are also our future main topics. 
TABLE 5: Running times of four algorithms.

\begin{tabular}{|c|c|c|c|c|}
\hline \multirow{2}{*}{$m \times n$} & \multicolumn{4}{|c|}{ Average running time (s) } \\
\hline & MOMA & $\mathrm{ACO}$ & ICA1 & New ICA \\
\hline $10 \times 5$ & 5.19 & 1.25 & 4.63 & 3.80 \\
\hline $20 \times 5$ & 6.14 & 5.31 & 4.22 & 4.42 \\
\hline $20 \times 8$ & 6.05 & 5.00 & 4.97 & 4.46 \\
\hline $30 \times 5$ & 15.11 & 18.13 & 10.48 & 10.33 \\
\hline $30 \times 8$ & 13.69 & 17.50 & 11.63 & 10.35 \\
\hline $30 \times 10$ & 13.69 & 18.13 & 11.13 & 10.51 \\
\hline $50 \times 5$ & 25.73 & 67.50 & 21.33 & 20.78 \\
\hline $50 \times 8$ & 25.64 & 67.59 & 20.24 & 20.00 \\
\hline $50 \times 10$ & 25.73 & 66.56 & 21.22 & 19.98 \\
\hline $50 \times 12$ & 25.88 & 66.46 & 20.31 & 20.04 \\
\hline $80 \times 8$ & 44.55 & 211.25 & 34.65 & 36.07 \\
\hline $80 \times 10$ & 45.05 & 217.50 & 33.07 & 36.70 \\
\hline $80 \times 12$ & 44.72 & 212.50 & 37.87 & 36.08 \\
\hline $80 \times 15$ & 44.42 & 216.22 & 30.89 & 35.95 \\
\hline $100 \times 10$ & 66.75 & 418.70 & 45.36 & 54.23 \\
\hline $100 \times 12$ & 64.84 & 410.94 & 51.27 & 52.14 \\
\hline $100 \times 15$ & 64.56 & 409.38 & 51.11 & 52.17 \\
\hline $120 \times 10$ & 88.80 & 682.50 & 72.84 & 75.63 \\
\hline $120 \times 12$ & 87.44 & 701.22 & 60.21 & 73.65 \\
\hline $120 \times 15$ & 87.08 & 697.55 & 74.18 & 73.39 \\
\hline $150 \times 10$ & 122.31 & 1251.30 & 107.39 & 101.70 \\
\hline $150 \times 15$ & 124.17 & 1246.91 & 85.04 & 104.15 \\
\hline $150 \times 20$ & 122.83 & 1231.56 & 97.04 & 115.22 \\
\hline $180 \times 10$ & 165.88 & 2235.00 & 107.81 & 145.10 \\
\hline $180 \times 15$ & 164.14 & 2060.00 & 107.14 & 141.40 \\
\hline $180 \times 20$ & 167.72 & 2030.07 & 109.95 & 138.26 \\
\hline $200 \times 10$ & 202.55 & 2798.43 & 138.81 & 182.48 \\
\hline $200 \times 15$ & 202.05 & 2854.68 & 129.42 & 177.57 \\
\hline $200 \times 20$ & 200.72 & 2843.42 & 156.61 & 177.95 \\
\hline $220 \times 15$ & 241.42 & 3743.75 & 189.67 & 202.34 \\
\hline $220 \times 20$ & 241.44 & 3781.25 & 155.95 & 201.76 \\
\hline
\end{tabular}

TABLE 6: Experimental results of Wilcoxon signed-rank test for new ICA and ACO.

\begin{tabular}{lccc}
\hline New ICA-ACO & Number & Mean rank & Sum of ranks \\
\hline Negative ranks & 30 & 15.50 & 0.00 \\
Positive ranks & 0 & & 0.00 \\
Ties & 1 & & \\
Total & 31 & p_value $=0.001$ & \\
& & & \\
\hline
\end{tabular}

TABLE 7: Experimental results of Wilcoxon signed-rank test for new ICA and MOMA.

\begin{tabular}{lccc}
\hline New ICA-MOMA & Number & Mean rank & Sum of ranks \\
\hline Negative ranks & 31 & 16.00 & 0.00 \\
Positive ranks & 0 & & 0.00 \\
Ties & 0 & & \\
Total & 31 & p_value $=0.001$ & \\
& & & \\
\hline
\end{tabular}


TABLE 8: Experimental results of Wilcoxon signed-rank test for new ICA and ICA1.

\begin{tabular}{lccc}
\hline New ICA-ICA1 & Number & Mean rank & Sum of ranks \\
\hline Negative ranks & 30 & 15.50 & 0.00 \\
Positive ranks & 0 & & 0.00 \\
Ties & 1 & & \\
Total & 31 & p_value $=0.001$ & \\
& & & \\
\hline
\end{tabular}

\section{Conflicts of Interest}

The authors declare that there are no conflicts of interest regarding the publication of this article.

\section{References}

[1] T. C. E. Cheng and C. C. S. Sin, "A state-of-the-art review of parallel-machine scheduling research," European Journal of Operational Research, vol. 47, no. 3, pp. 271-292, 1990.

[2] Z. Li, H. Yang, S. Zhang, and G. Liu, "Unrelated parallel machine scheduling problem with energy and tardiness cost," The International Journal of Advanced Manufacturing Technology, vol. 84, no. 1-4, pp. 213-226, 2016.

[3] P. Liang, H.-D. Yang, G.-S. Liu, and J.-H. Guo, "An ant optimization model for unrelated parallel machine scheduling with energy consumption and total tardiness," Mathematical Problems in Engineering, vol. 2015, Article ID 907034, 8 pages, 2015.

[4] K. Li, X. Zhang, J. Y.-T. Leung, and S.-L. Yang, "Parallel machine scheduling problems in green manufacturing industry," Journal of Manufacturing Systems, vol. 38, pp. 98-106, 2016.

[5] A. Che, Y. Zeng, and K. Lyu, "An efficient greedy insertion heuristic for energy-conscious single machine scheduling problem under time-of-use electricity tariffs," Journal of Cleaner Production, vol. 129, pp. 565-577, 2016.

[6] Y.-C. Wang, M.-J. Wang, and S.-C. Lin, "Selection of cutting conditions for power constrained parallel machine scheduling," Robotics and Computer-Integrated Manufacturing, vol. 43, pp. 105-110, 2017.

[7] S.-W. Lin, K.-C. Ying, W.-J. Wu, and Y.-I. Chiang, "Multiobjective unrelated parallel machine scheduling: A Tabuenhanced iterated Pareto greedy algorithm," International Journal of Production Research, vol. 54, no. 4, pp. 1110-1121, 2016.

[8] K. C. Ying, "A multi-point simulated annealing heuristic for solving multiple objective unrelated parallel machine scheduling problems," International Journal of Production Research, vol. 53, pp. 1065-1076, 2015.

[9] X. Li, F. Yalaoui, L. Amodeo, and H. Chehade, "Metaheuristics and exact methods to solve a multiobjective parallel machines scheduling problem," Journal of Intelligent Manufacturing, vol. 23, no. 4, pp. 1179-1194, 2012.

[10] K. Deb, S. Agrawal, A. Pratap, and T. Meyarivan, "A fast elitist non-dominated sorting genetic algorithm for multi-objective optimization: NSGA-II," in Parallel Problem Solving from Nature PPSN VI, vol. 1917 of Lecture Notes in Computer Science, pp. 849-858, Springer, Berlin, Germany, 2000.

[11] S. H. Pakzad-Moghaddam, "A Lévy flight embedded particle swarm optimization for multi-objective parallel-machine scheduling with learning and adapting considerations," Computers \& Industrial Engineering, vol. 91, pp. 109-128, 2016.
[12] M. Afzalirad and J. Rezaeian, "A realistic variant of bi-objective unrelated parallel machine scheduling problem: NSGA-II and MOACO approaches," Applied Soft Computing, vol. 50, pp. 109123, 2017.

[13] M. H. F. Zarandi and V. Kayvanfar, "A bi-objective identical parallel machine scheduling problem with controllable processing times: a just-in-time approach," The International Journal of Advanced Manufacturing Technology, vol. 77, no. 1-4, pp. 545563, 2015.

[14] E. Atashpaz-Gargari and C. Lucas, "Imperialist competitive algorithm: an algorithm for optimization inspired by imperialistic competition," in Proceedings of the IEEE Congress on Evolutionary Computation (CEC '07), pp. 4661-4667, September 2007.

[15] Z. Ardalan, S. Karimi, O. Poursabzi, and B. Naderi, "A novel imperialist competitive algorithm for generalized traveling salesman problems," Applied Soft Computing, vol. 26, pp. 546$555,2015$.

[16] A. Kaveh and S. Talatahari, "Optimum design of skeletal structures using imperialist competitive algorithm," Computers \& Structures, vol. 88, no. 21-22, pp. 1220-1229, 2010.

[17] S. Hosseini, A. A. Khaled, and S. Vadlamani, "Hybrid imperialist competitive algorithm, variable neighborhood search, and simulated annealing for dynamic facility layout problem," Neural Computing and Applications, vol. 25, no. 7-8, pp. 18711885, 2014.

[18] K. Lian, C. Zhang, L. Gao, and X. Shao, "Single row facility layout problem using an imperialist competitive algorithm," in Proceedings of the in Proceedings of the 41st International Conference on Computers and Industrial Engineering, pp. 578586, 2011.

[19] B. Mohammadi-ivatloo, A. Rabiee, A. Soroudi, and M. Ehsan, "Imperialist competitive algorithm for solving non-convex dynamic economic power dispatch," Energy, vol. 44, no. 1, pp. 228-240, 2012.

[20] M. Bagher, M. Zandieh, and H. Farsijani, "Balancing of stochastic U-type assembly lines: An imperialist competitive algorithm," The International Journal of Advanced Manufacturing Technology, vol. 54, no. 1-4, pp. 271-285, 2011.

[21] Z. Wei, J. Yan, Y. Li, C. Xia, and J. Zheng, "Imperialist competitive algorithm for assembly sequence planning," The International Journal of Advanced Manufacturing Technology, vol. 67, no. 9-12, pp. 2207-2216, 2013.

[22] B. Wang, Z. Guan, D. Li, C. Zhang, and L. Chen, "Twosided assembly line balancing with operator number and task constraints: a hybrid imperialist competitive algorithm," The International Journal of Advanced Manufacturing Technology, vol. 74, no. 5-8, pp. 791-805, 2014.

[23] M. A. Ahmadi, M. Ebadi, A. Shokrollahi, and S. M. J. Majidi, "Evolving artificial neural network and imperialist competitive 
algorithm for prediction oil flow rate of the reservoir," Applied Soft Computing, vol. 13, no. 2, pp. 1085-1098, 2013.

[24] K. Devika, A. Jafarian, and V. Nourbakhsh, "Designing a sustainable closed-loop supply chain network based on triple bottom line approach: a comparison of metaheuristics hybridization techniques," European Journal of Operational Research, vol. 235, no. 3, pp. 594-615, 2014.

[25] J. Behnamian and M. Zandieh, "A discrete colonial competitive algorithm for hybrid flowshop scheduling to minimize earliness and quadratic tardiness penalties," Expert Systems with Applications, vol. 38, no. 12, pp. 14490-14498, 2011.

[26] S. M. Goldansaz, F. Jolai, and A. H. Zahedi Anaraki, "A hybrid imperialist competitive algorithm for minimizing makespan in a multi-processor open shop," Applied Mathematical Modelling: Simulation and Computation for Engineering and Environmental Systems, vol. 37, no. 23, pp. 9603-9616, 2013.

[27] D. Lei, M. Li, and L. Wang, "A two-phase meta-heuristic for multiobjective flexible job shop scheduling problem with total energy consumption threshold," IEEE Transactions on Cybernetics, pp. 1-13, 2018.

[28] B. Naderi and M. Yazdani, "A model and imperialist competitive algorithm for hybrid flow shops with sublots and setup times," Journal of Manufacturing Systems, vol. 33, no. 4, pp. 647-653, 2014.

[29] A. Mortazavi, A. A. Khamseh, and B. Naderi, "A novel chaotic imperialist competitive algorithm for production and air transportation scheduling problems," Neural Computing and Applications, vol. 26, no. 7, pp. 1709-1723, 2015.

[30] S. Forouharfard and M. Zandieh, "An imperialist competitive algorithm to schedule of receiving and shipping trucks in cross-docking systems," The International Journal of Advanced Manufacturing Technology, vol. 51, no. 9-12, pp. 1179-1193, 2010.

[31] P. Zhang, Y. Lv, and J. Zhang, "An improved imperialist competitive algorithm based photolithography machines scheduling," International Journal of Production Research, pp. 1-13, 2017.

[32] N. Karimi, M. Zandieh, and A. A. Najafi, "Group scheduling in flexible flow shops: A hybridised approach of imperialist competitive algorithm and electromagnetic-like mechanism," International Journal of Production Research, vol. 49, no. 16, pp. 4965-4977, 2011.

[33] S. Karimi, Z. Ardalan, B. Naderi, and M. Mohammadi, "Scheduling flexible job-shops with transportation times: mathematical models and a hybrid imperialist competitive algorithm," Applied Mathematical Modelling: Simulation and Computation for Engineering and Environmental Systems, vol. 41, pp. 667-682, 2017.

[34] H. Seidgar, M. Zandieh, H. Fazlollahtabar, and I. Mahdavi, "Simulated imperialist competitive algorithm in two-stage assembly flow shop with machine breakdowns and preventive maintenance," Proceedings of the Institution of Mechanical Engineers, Part B: Journal of Engineering Manufacture, vol. 230, no. 5, pp. 934-953, 2016.

[35] S. Hosseini and A. Al Khaled, "A survey on the Imperialist Competitive Algorithm metaheuristic: Implementation in engineering domain and directions for future research," Applied Soft Computing, vol. 24, pp. 1078-1094, 2014.

[36] L. Jin, C. Zhang, X. Shao, X. Yang, and G. Tian, "A multiobjective memetic algorithm for integrated process planning and scheduling," The International Journal of Advanced Manufacturing Technology, vol. 85, no. 5-8, pp. 1513-1528, 2016.
[37] U. Güvenç and F. Katırcıoğlu, "Escape velocity: a new operator for gravitational search algorithm," Neural Computing and Applications, pp. 1-16, 2017.

[38] A. Zhang, G. Sun, Z. Wang, and Y. Yao, "A hybrid genetic algorithm and gravitational search algorithm for global optimization," Neural Network World, vol. 25, no. 1, pp. 53-73, 2015. 


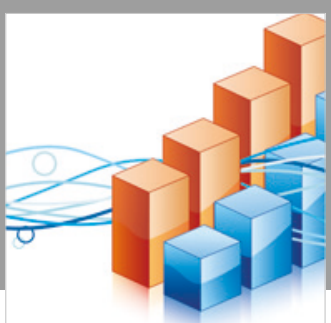

Advances in

Operations Research

\section{-n-m}
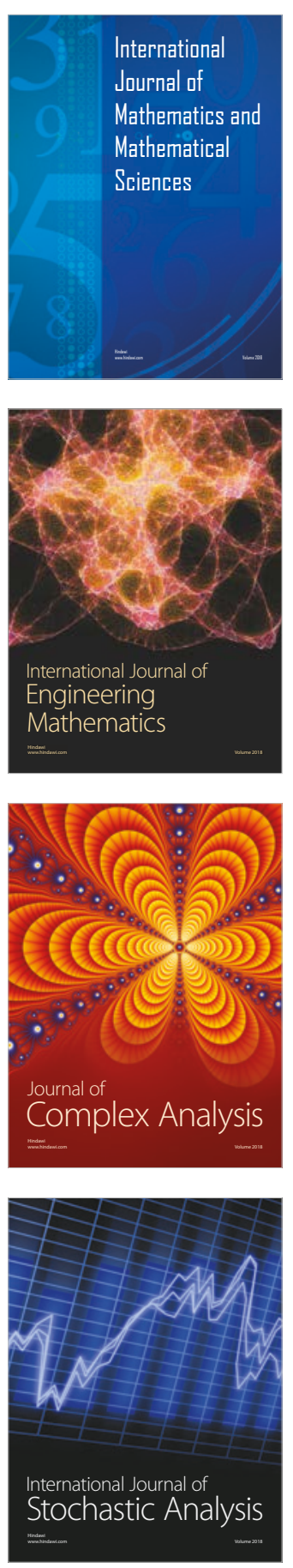
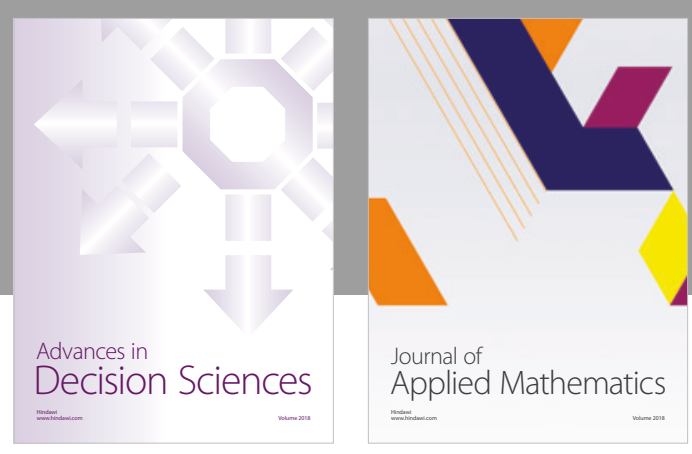

Journal of

Applied Mathematics
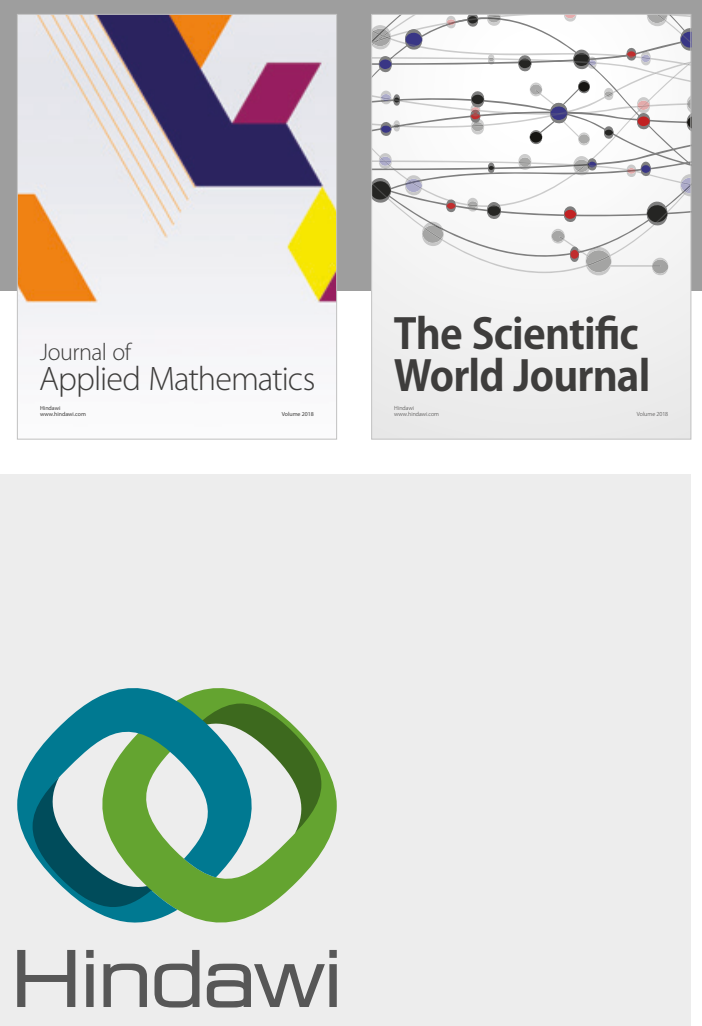

Submit your manuscripts at

www.hindawi.com

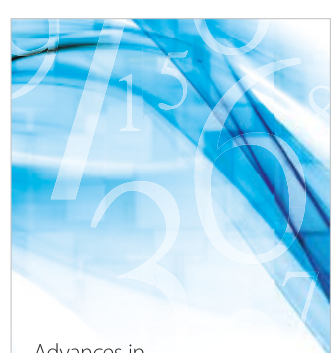

Advances in
Numerical Analysis
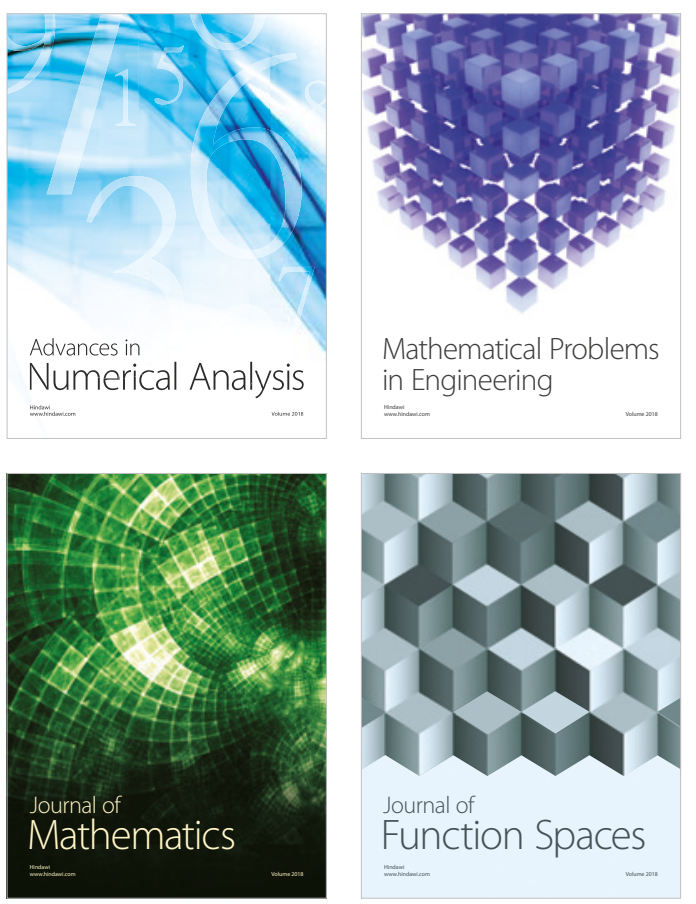

Mathematical Problems in Engineering

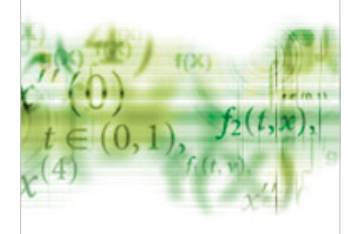

International Journal of

Differential Equations

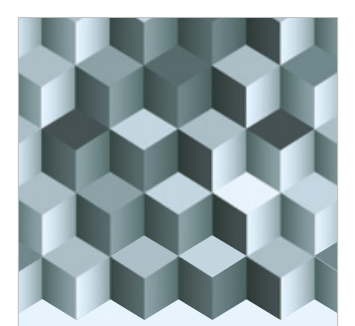

Journal of

Function Spaces

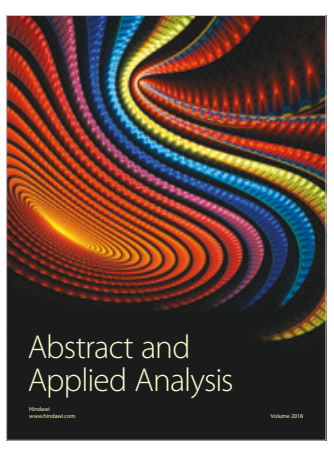

The Scientific

World Journal

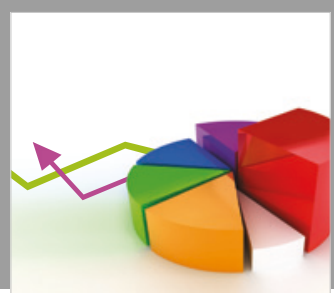

Journal of

Probability and Statistics
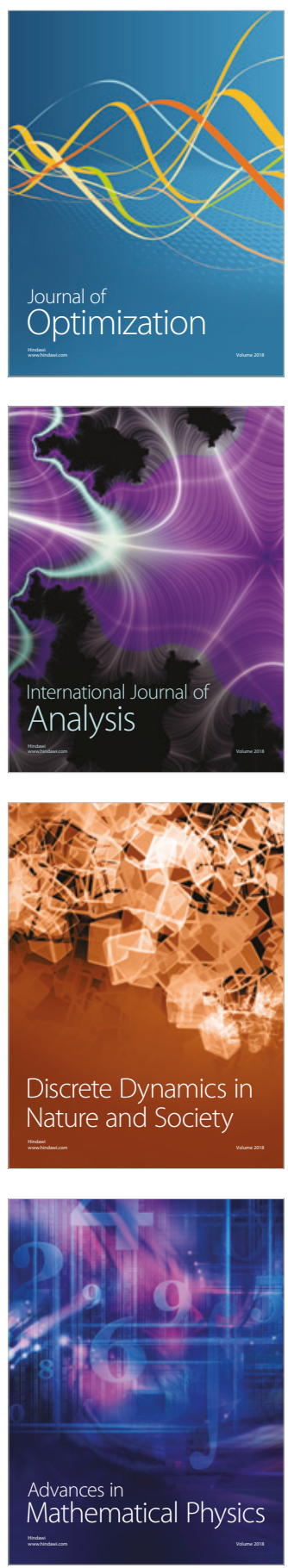